\title{
Gram per Gram
}

National Cancer Institute

\section{Source}

National Cancer Institute. Gram per Gram. NCI Thesaurus. Code C70453.

A unit of a mass fraction expressed as a number of grams of substance per gram of mixture. The unit is also used as a dose calculation unit. 